\title{
Suboccipital Retrocondylar Approach for an Anterolateral Foramen Magnum Meningioma
}

\author{
Adrian Balașa ${ }^{1,2}$ Gabriel Gyorki ${ }^{2}$ Flaviu Tamas ${ }^{2}$ Corina Hurghis ${ }^{2}$ Rares Chinezu ${ }^{1,2}$ \\ ${ }^{1}$ Department of Neurosurgery, George Emil Palade University of \\ Medicine, Pharmacy, Science, and Technology of Tîrgu Mureș, Tîrgu \\ Mureș, Romania \\ 2 Department of Neurosurgery, Tîrgu Mureș County Clinical \\ Emergency Hospital, Tîrgu Mureș, Romania \\ Address for correspondence Adrian Balașa, MD, PhD, Clinica de \\ Neurochirugie, Spitalul Clinic Județean de Urgentă Tîrgu Mureș, Street \\ Gheorge Marinescu, Nr 50., 540136 Tîrgu Mureș, Mureș, Romania \\ (e-mail: adrian.balasa@yahoo.fr).
}

J Neurol Surg B 2021;82(suppl S1):S33-34.

\begin{abstract}
\section{Keywords}

- foramen magnum meningioma

- retrocondylar approach

- skull base

- dynamic retraction

Objectives This study was to demonstrate surgical technique for an anterolateral foramen magnum meningioma.

Design Present study is presented through an operative video.

Setting This study is conducted at the Department of Neurosurgery, Tîrgu Mureș, Romania. Participants A 62-year-old female is the participant who was diagnosed with a foramen magnum meningioma.

Main Outcome Measures Complete surgical resection of the tumor with no postoperative deficits or complications.

Results A 62 years-old female was admitted for left hemilingual atrophia, dysphonia, right hemiparesis grade 2 of 5 , right hemihypesthesia, and cervical pain. The magnetic resonance imaging (MRI) showed a right foramen magnum meningioma, sized approximately $2 \mathrm{~cm}$ in all planes (-Fig. 1). This was classified with the Bernard system as an intradural foramen magnum meningioma with anterolateral insertion to the dura mater and below the vertebral artery. A suboccipital, retrocondylar, and c1 right hemilaminectomy approach was performed. Using microsurgical tumoral decompression techniques, ultrasonic aspiration, and following the natural cleavage planes, complete tumor removal was achieved (-Fig. 2). The patient presented an uneventful postoperative course with no postoperative new neurological deficits and was discharged at home 7 days following surgery. Control MRI at 6 months (-Fig. 1 ) and 2 years showed no tumor residue or recurrence. Neurologic status at 6 months was excellent, showing complete remission of symptoms.

Conclusion Retrocondylar suboccipital approach is a safe and feasible option for anterolateral foramen magnum meningiomas provided that natural corridors and dynamic retraction are used.

The link to the video can be found at: https://youtu.be/jpxMcjCpN6E.
\end{abstract}

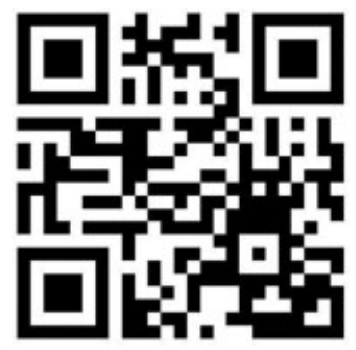

received

February 25, 2019 accepted after revision

March 8, 2020

published online

December 31, 2020

Conflict of Interest

None declared.

www.thieme.com/skullbasevideos

www.thieme.com/jnlsbvideos

DOI https://doi.org/

10.1055/s-0040-1714403. ISSN 2193-6331. (c) 2020. The Author(s).

This is an open access article published by Thieme under the terms of the Creative Commons Attribution-NonDerivative-NonCommercial-License, permitting copying and reproduction so long as the original work is given appropriate credit. Contents may not be used for commercial purposes, or adapted, remixed, transformed or built upon. (https://creativecommons.org/ licenses/by-nc-nd/4.0/)

Georg Thieme Verlag KG, Rüdigerstraße 14, 70469 Stuttgart, Germany 

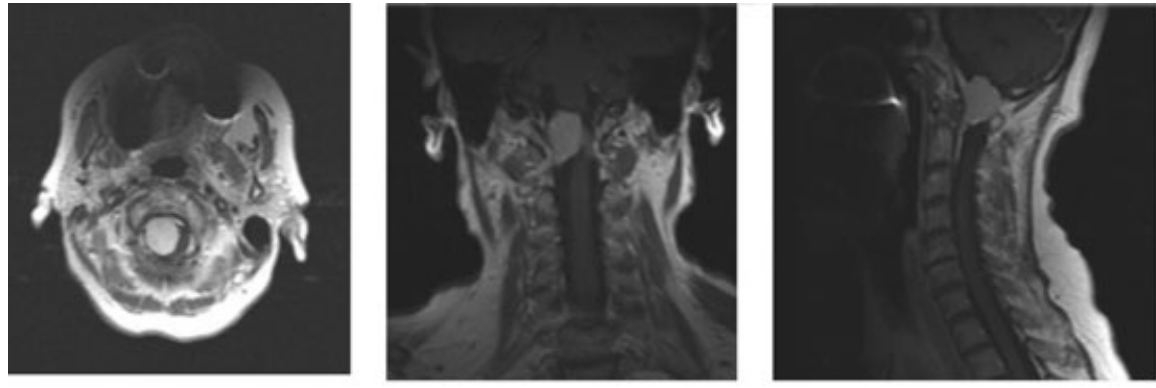

\section{Preoperative MRI}
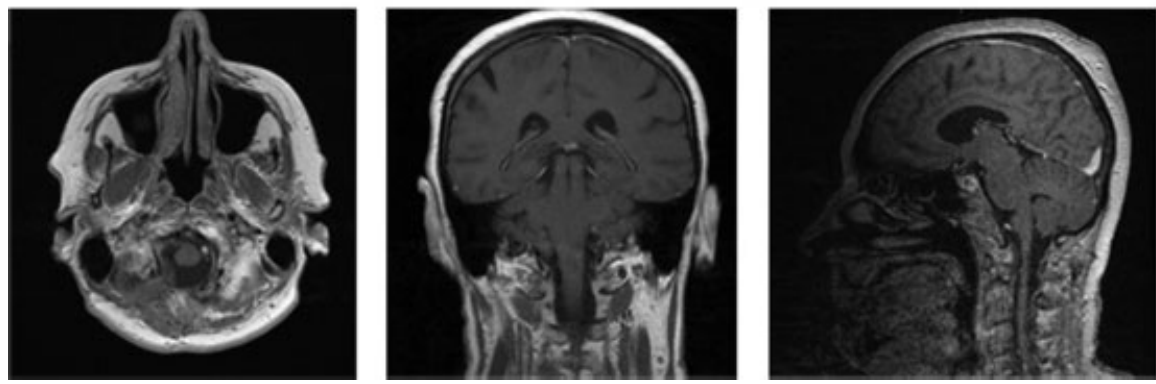

\section{Postoperative MRI}

Fig. 1 Preoperative and postoperative imaging of the foramen magnum meningioma. MRI, magnetic resonance imaging.

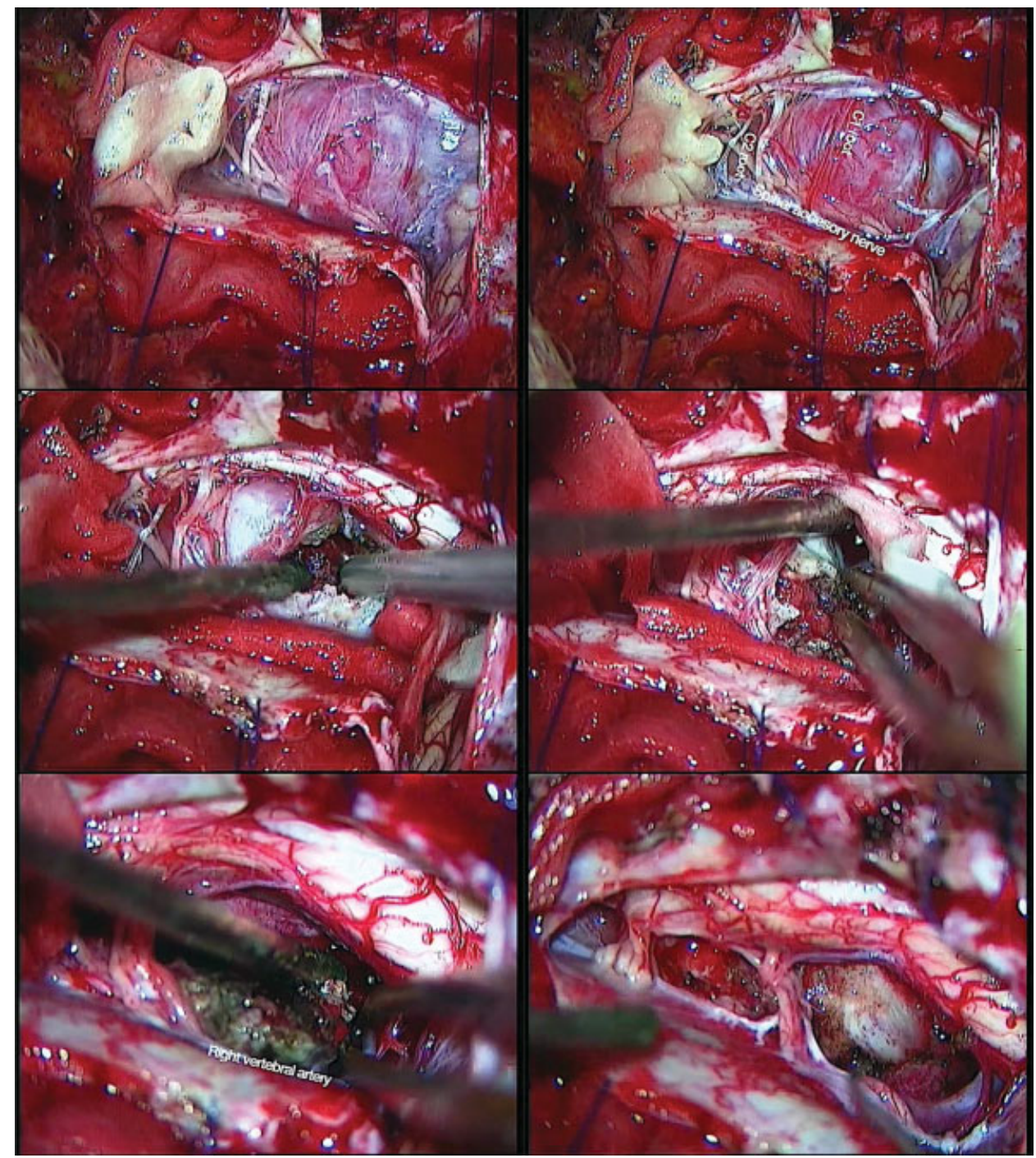

Fig. 2 Various intraoperative aspects showing: initial aspect of tumor and local anatomy, spinal accessory nerve, right c1 and c2 roots, tumor resection using natural corridors, identification of right vertebral artery, and final postoperative aspect showing complete resection. 